\title{
Case study of effective current estimation in main circuit of tram vehicle
}

\author{
Karol Chyła ${ }^{1, *}$, Marcin Urbański ${ }^{1}$, Dominik Sawuła ${ }^{1}$, and Stanisław Rawicki ${ }^{2}$ \\ ${ }^{1}$ Solaris Tram Sp. z o.o, Poland \\ ${ }^{2}$ Poznan University of Technology, Faculty of Electrical Engineering, Poland
}

\begin{abstract}
Currently the trams are experiencing the renaissance and more and more Polish cities decide to renew the fleet. New vehicles are usually characterized by high transport capacity, low floor, climate comfort, crash resistance, low energy consumption and low axle loads. Such requirements can only be achieved through optimization in many areas of the vehicle's construction. One of such tasks is the optimal selection of components of the main circuit installation and traction needs. The paper is oriented on the issue of engineering modelling of the effective values of currents flowing in the main circuit and the tramway traction needs circuits. Due to the non-periodic nature of the vehicle traffic loads in urban traffic, the optimal selection of the performance parameters helps in better selection of conductor cross sections, filters and safeguards. A better selection of these components means a reduction of its weight, which is extremely important for meet basic requirements of modern tram vehicles. The paper is intended to gather the experience of authors in this field of knowledge and compares several modelling strategies that the authors use during designing tram vehicles. The elaboration summarizes the results obtained using different modelling strategies, and shows correlation between effective value and selection of components.
\end{abstract}

\section{Tram main circuit}

Effective current (RMS value) which flows in main circuit, is one of basic parameter, which allows to choose the correct components for this circuit. Main circuit in tram vehicle is a part of its electric installation, which main function is to provide power supply from pantograph, so from catenary net, to main loads: Traction converter, Auxiliary converter, HVAC, and others which has supply direct from catenary voltage. This paper focuses mainly over this part of main circuit, which is supplying traction converter. The main circuit of simulated tram is presented in Fig. 1a and in Fig. 1 b.

The simulated tram has one pantograph with positive potential, four motorized bogies with two motors each, and four independently supply of traction converters. All other loads are omitted because they are not important according to goal of this paper. Ground potential is reached via brush contacts assembled on axles in each motorized bogie.

\section{Components assign}

The most visible influence of the effective current could be observed during selection of fuses and wires cross section. That's why this paper focuses mostly on selection those components. Optimized selection of components of main circuit has to assure safety as well as reliable operations during long exploitation. Safety assurance in (a)

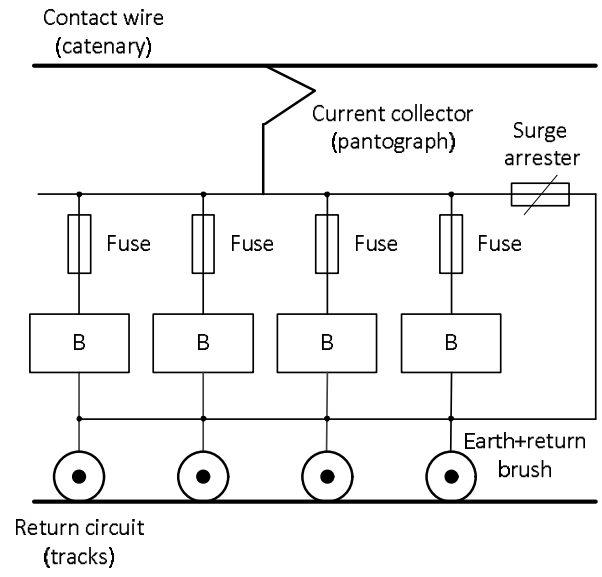

(b)

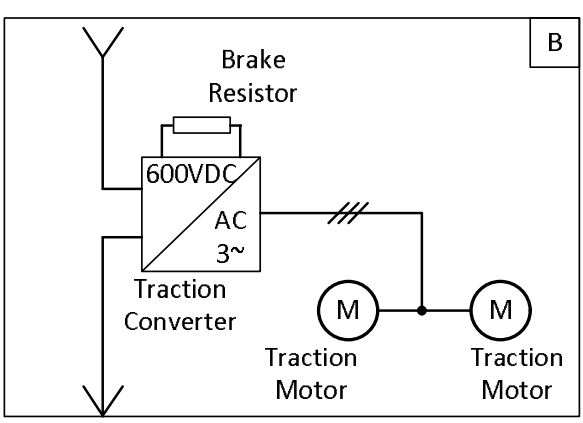

Fig. 1. Scheme of simulated tram: (a) main circuit; (b) one of four identical blocks B consisting of traction converter, braking resistor and two identical traction motors.

Corresponding author: karol.chyla@solaristram.com 
tram vehicle is mainly defined by standards like EN 60077-1 [3], EN 60077-2 [4], EN 60077-5 [5] EN 50355 [2], EN 50343[1], HD 60364 [6]. however, to ensure the long operation periods is related with the achievement of the best ratio of MTBF and/or the entire circuit MTTF main, and the lowest LCC costs.

In this paper it is present traction converter circuit fuse and traction converter cable selection process. On the first step of components selection to vehicle main circuit is fuse characteristic selection. Generally fuse characteristic "aR" or "gR" is most suitable for traction converter overcurrent protection. In next step we are defined the fuse minimal rated current value by the following equation:

$$
\begin{aligned}
& I_{n} \geq I_{\text {rated }} \\
& I_{\text {rated }}=\frac{I_{B}}{A}
\end{aligned}
$$

$I_{B}[\mathrm{~A}]$ - traction converter input RMS current; $I_{\text {rated }}[\mathrm{A}]$ - fuse minimal rated current;

$I_{n}[\mathrm{~A}]$ - fuse nominal current; $A=0,462$ - reduction factor depending on: ambient temperature, ventilation air speed, operation mode.

For the most critical route section is necessary to achieve safe distance between traction converter input RMS current and fuse let-through current in specific time. Such verification is made according to the equation:

$$
I_{T T C} \geq \frac{I_{B n}}{B}
$$

$I_{\text {TTC }}[\mathrm{A}]$ - fuse let-through current in specific time is defined according fuse time-current characteristic; $I_{B n}[\mathrm{~A}]$ - traction converter input RMS current in specific time;

$B=0,5$ - fuse time-current characteristic reduction factor.

Second design phase it is traction converter supply cable selection. During cable selection is necessary to focus of many topics, but in this part we consider only selection in respect to traction converter load current.

When fuse nominal current value was defined we can select traction converter supply cable cross-section (CSA).

Minimal required value of traction converter supply cable cross-section is defined by equation (base on EN50343 [1]).

$$
\begin{gathered}
I_{n} \leq I_{z} \\
I_{z}=I_{\text {cable }} \times K
\end{gathered}
$$

$I_{n}[\mathrm{~A}]$ - fuse nominal current;

$I_{z}[\mathrm{~A}]$ - maximal permissible current of traction converter supply cable;

$I_{\text {cable }}[\mathrm{A}]$ - nominal current of traction converter supply cable;
$K=0,776$ - reduction factor dependent on: ambient temperature, installation type, cable conductor temperature, operation mode.

After selection of traction converter fuse and traction converter power supply cable it is necessary to verify coordination between fuse and cable. Coordination verification is based on EN 50343 [1] standard.

Proper cable protection against overload is described by equation below:

$$
1,6 \times I_{n} \leq 1,45 \times I_{z}
$$

$I_{n}[\mathrm{~A}]$ - fuse nominal current;

$I_{z}[\mathrm{~A}]-$ maximal permissible current of traction converter supply cable.

Negative verification results force the changes of main circuit components or other design parameters for example higher class of electrical insulation. Many times it is necessary to use forced ventilation or even liquid cooling.

In some circumstances it is necessary to use additional thermal insulation which eliminates overheating of elements used during maintenance operations i.e. flap handle.

RMS current value also influences on many components not related to components of main circuit such as: hosing dimension, cooling method, thermal insulation solution, vehicle space arrangement.

As we can see the proper calculation of traction RMS current has high influence on safety and value of main circuit components LLC costs.

As we can see traction RMS current influences on many design areas.

The goal of below calculations is to present how traction RMS current has influence on main circuit components selection.

\section{Simulation parametrization}

In view of the fact that trams movement has non-periodic character, there has to be performed simulations of theoretical substitution movements scenarios, base on which, the reference effective value of current is estimated, and used for further components choosing.

Very interesting is fact that to create correct scenarios and assign right parameters to simulations, designer needs to firstly study infrastructure data like: numbers of his, average stop distance, factor of non-collision tracks, maximal and average speed, and general time schedules, all those data has influence on parameters selected to simulation.

For purpose of this paper there were performed four simulation scenarios:

Scenario 1 - phase of acceleration, phase of constant speed drive, phase of braking without recuperation to catenary (Fig. 2);

Scenario 2 - phase of acceleration, phase of constant speed drive, phase of braking with recuperation to catenary (Fig. 3); 
Scenario 3 - phase of acceleration, phase of service braking with recuperation to catenary (Fig. 4);

Scenario 4 - phase of acceleration, phase of service braking with recuperation to catenary (Fig. 5).

For these scenarios 1,2,3 there were defined the same infrastructure and vehicle parameters :

- distance between stops is defined on $500 \mathrm{~m}$;

- slope $1,5 \%$;

- tram loaded on $2 / 3$ of nominal load $-72200 \mathrm{~kg}$.

The time schedule for scenario 1, 2 was defined base on maximal allowed tram speed $-50 \mathrm{~km} / \mathrm{h}$, drive time is $50 \mathrm{~s}$ and stop time is $20 \mathrm{~s}$.

Scenario 3 was defined as case where after maximal acceleration to maximal speed $50 \mathrm{~km} / \mathrm{h}$ was performed maximal service braking with recuperation.

Scenario 4 was defined by parameters:

- distance between stops is defined on $500 \mathrm{~m}$

- slope 6\%

- tram loaded on $2 / 3$ of nominal load - 72200kg.

On purpose of choosing fuses and wires it was defined that according to simulated tram, that effective current for one traction converter is $1 / 4$ of traction current for whole vehicle. For simulation there was omitted current flows for auxiliaries and HVAC systems.

The assumed values allowed to model the traction current, allowing to complete the timetable on the reference section. The time of each driving phase is shown in Table 1.

Table 1. Time of phases for each scenario.

\begin{tabular}{|c|c|c|c|c|}
\hline Scenario & 1 & 2 & 3 & 4 \\
\cline { 2 - 5 } & $\begin{array}{c}\text { Time } \\
{[\mathrm{s}]}\end{array}$ & $\begin{array}{c}\text { Time } \\
{[\mathrm{s}]}\end{array}$ & $\begin{array}{c}\text { Time } \\
{[\mathrm{s}]}\end{array}$ & $\begin{array}{c}\text { Time } \\
{[\mathrm{s}]}\end{array}$ \\
\hline $\begin{array}{c}\text { Acceleration } \\
\text { to } 50 \mathrm{~km} / \mathrm{h}\end{array}$ & 21,23 & 21,23 & 21,23 & 39,8 \\
\hline $\begin{array}{c}\text { Constant } \\
\text { speed } \\
50 \mathrm{~km} / \mathrm{h}\end{array}$ & 17,58 & 17,58 & 0 & 0 \\
\hline $\begin{array}{c}\text { Braking } \\
\text { from } \\
50 \mathrm{~km} / \mathrm{h} \text { to } \\
\text { standstill }\end{array}$ & $12,29 *$ & 12,29 & 12,29 & 10,64 \\
\hline $\begin{array}{c}\text { Stop } \\
\text { standstill }\end{array}$ & 20 & 20 & 20 & 20 \\
\hline Travel time & 71,1 & 71,1 & 53,52 & 70,44 \\
\hline
\end{tabular}

\section{Scenario simulation}

\subsection{Scenario 1}

Fuse nominal current selection $\left(I_{n}\right)$.based on RMS1 current characteristic $\left(I_{B}\right)$

$$
\begin{gathered}
I_{n} \geq I_{\text {rated }} \\
I_{\text {rated }}=\frac{I_{B}}{A}=\frac{145,05}{0,462}=313,31[\mathrm{~A}] \\
I_{n}=315[\mathrm{~A}]
\end{gathered}
$$

$I_{B}=145,05[\mathrm{~A}]$ - traction converter input RMS current;
$I_{\text {rated }}[\mathrm{A}]$ - fuse minimal rated current;

$I_{n}[\mathrm{~A}]$ - fuse nominal current;

$A=0,462$ - reduction factor depend on: ambient temperature, ventilation air speed, operation mode.

For each driving phase RMS2 current should be compared with fuse let-through to eliminate fuse melting

$$
\begin{gathered}
I_{T T C} \geq \frac{I_{B 1}}{B} \\
1400[A] \geq \frac{304,393[A]}{0,5} \\
1400[A] \geq 608,786[A]
\end{gathered}
$$

$I_{T T C}=1400[\mathrm{~A}]-$ fuse let-through current in 10,77 [s] is defined according fuse time-current characteristic; $I_{B I}=304,393[\mathrm{~A}]$ - traction converter input RMS current starting;

$B=0,5$ - fuse time-current characteristic reduction factor.

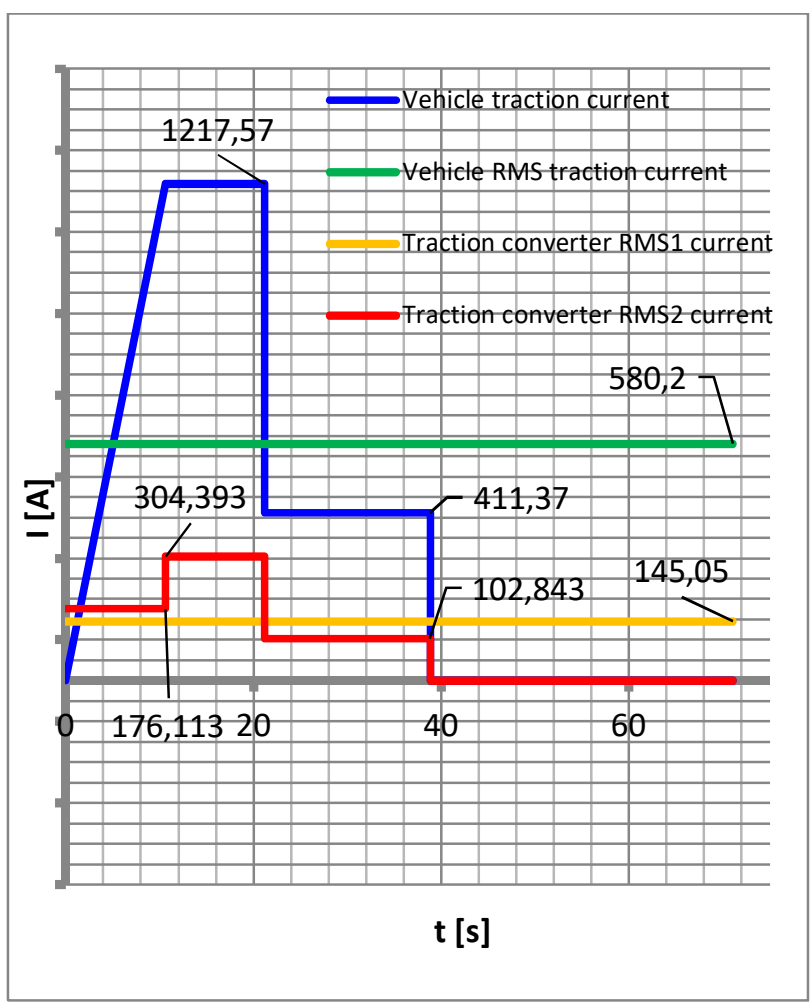

Fig. 2. Traction current and RMS current for vehicle and traction converter.

Cable selection is made in calculations below:

$$
\begin{gathered}
I_{n} \leq I_{z} \\
I_{z}=I_{\text {cable }} \times K \\
I_{z}=507 \times 0,776=393,43[\mathrm{~A}] \\
315[\mathrm{~A}] \leq 393,43
\end{gathered}
$$

$I_{n}=315[\mathrm{~A}]-$ fuse nominal current; 
$I_{z}[\mathrm{~A}]$ - Maximal permissible current of traction converter supply cable;

$I_{\text {cable }}=507[\mathrm{~A}]-$ Nominal current of traction converter supply cable $95 \mathrm{~mm}^{2}$;

$K=0,776$ - Reduction factor depend on: ambient temperature, installation type, cable conductor temperature, operation mode.

Proper cable protection against overload is verified by the following calculation:

$$
\begin{gathered}
1,6 \times I_{n} \leq 1,45 \times I_{z} \\
1,6 \times 315 \leq 1,45 \times 393,43 \\
504[A] \leq 570,47[A]
\end{gathered}
$$

$I_{n}=315[\mathrm{~A}]-$ fuse nominal current;

$I_{z}=393,43[\mathrm{~A}]-$ maximal permissible current of traction converter supply cable.

\subsection{Scenario 2}

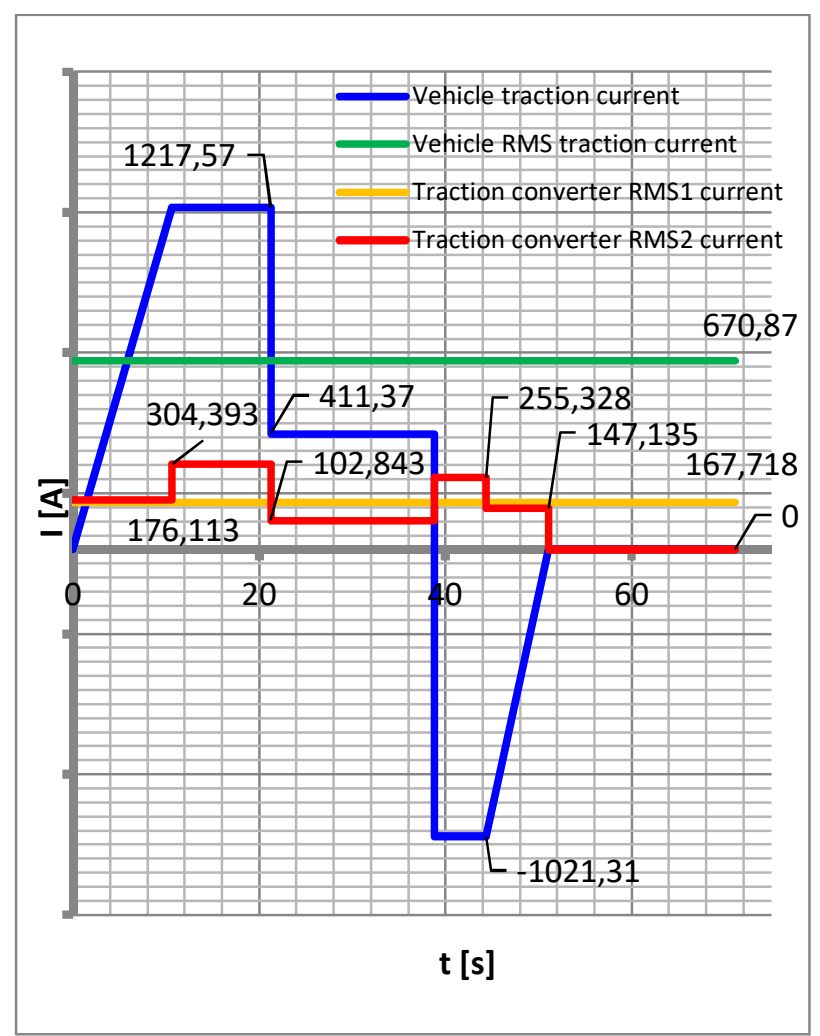

Fig. 3. Traction current and RMS current for vehicle and traction converter.

Fuse nominal current selection $\left(I_{n}\right)$.based on RMS1 current characteristic $\left(I_{B}\right)$.

$$
\begin{gathered}
I_{n} \geq I_{n \min } \\
I_{n \min }=\frac{I_{B}}{A}=\frac{167,72}{0,462}=363,02[A] \\
I_{n}=400[\mathrm{~A}]
\end{gathered}
$$

$I_{B}=167,02[\mathrm{~A}]-$ traction converter input RMS current; $I_{\text {rated }}[\mathrm{A}]$ - fuse minimal rated current;

$I_{n}[\mathrm{~A}]$ - fuse nominal current;

$A=0,462$ - reduction factor depend on: ambient temperature, ventilation air speed, operation mode.

For each driving phase RMS2 current should be compared with fuse let-through to eliminate fuse melting:

$$
\begin{gathered}
I_{T T C} \geq \frac{I_{B 1}}{B} \\
1750[A] \geq \frac{304,393[A]}{0,5} \\
1750[A] \geq 608,786[A]
\end{gathered}
$$

$I_{T T C}=1750[\mathrm{~A}]$ - fuse let-through current in $10,77[\mathrm{~s}]$ is defined according fuse time-current characteristic;

$I_{B I}=304,393[\mathrm{~A}]$ - traction converter input RMS current starting;

$B=0,5$ - fuse time-current characteristic reduction factor.

Cable selection is made in calculations below:

$$
\begin{gathered}
I_{n} \leq I_{z} \\
I_{z}=I_{\text {cable }} \times K \\
I_{z}=599 \times 0,776=464,82[A] \\
400[A] \leq 464,82
\end{gathered}
$$

$I_{n}=400[\mathrm{~A}]-$ fuse nominal current

$I_{z}[\mathrm{~A}]-$ maximal permissible current of traction converter supply cable

$I_{\text {cable }}=599[\mathrm{~A}]-$ nominal current of traction converter supply cable $120 \mathrm{~mm}^{2}$;

$K=0,776$ - reduction factor depend on: ambient temperature, installation type, cable conductor temperature, operation mode.

Proper cable protection against overload is verified by calculation below:

$$
\begin{gathered}
1,6 \times I_{n} \leq 1,45 \times I_{z} \\
1,6 \times 400 \leq 1,45 \times 464,82 \\
640[A] \leq 674[A]
\end{gathered}
$$

$I_{n}=400[\mathrm{~A}]-$ fuse nominal current;

$I_{z}=464,82[\mathrm{~A}]-$ maximal permissible current of traction converter supply cable.

\subsection{Scenario 3}

Fuse nominal current selection $\left(I_{n}\right)$.based on RMS1 current characteristic $\left(I_{B}\right)$.

$$
I_{n} \geq I_{n \min }
$$




$$
\begin{gathered}
I_{n \min }=\frac{I_{B}}{A}=\frac{185,275}{0,462}=401,01[A] \\
I_{n}=450[A]
\end{gathered}
$$

$I_{B}=185,275[\mathrm{~A}]-$ traction converter input RMS current; $I_{\text {rated }}[\mathrm{A}]$ - fuse minimal rated current;

$I_{n}[\mathrm{~A}]$ - fuse nominal current;

$A=0,462$ - feduction factor depend on: ambient temperature, ventilation air speed, operation mode.

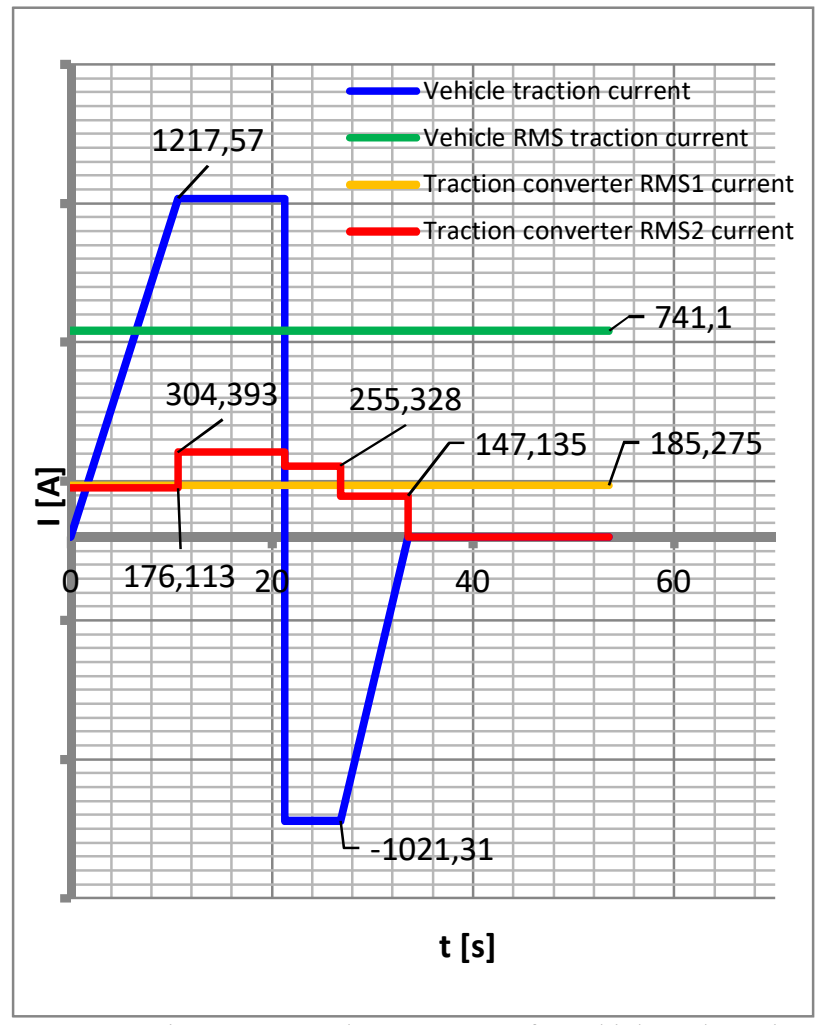

Fig. 4. Traction current and RMS current for vehicle and traction converter.

For each driving phase RMS2 current should be compared with fuse let-through to eliminate fuse melting:

$$
\begin{gathered}
I_{T T C} \geq \frac{I_{B 1}}{B} \\
2800[A] \geq \frac{304,393[A]}{0,5} \\
2800[A] \geq 608,786[A]
\end{gathered}
$$

$I_{T T C}=2800[\mathrm{~A}]$ - fuse let-through current in 10,77 [s] is defined according fuse time-current characteristic;

$I_{B I}=304,393$ [A] - traction converter input RMS current starting;

$B=0,5$ - fuse time-current characteristic reduction factor.

Cable selection is made in calculations below:

$$
\begin{gathered}
I_{n} \leq I_{z} \\
I_{z}=I_{\text {cable }} \times K
\end{gathered}
$$

$$
\begin{gathered}
I_{z}=691 \times 0,776=536,21[A] \\
350[A] \leq 536,21[A]
\end{gathered}
$$

$I_{n}=350[\mathrm{~A}]-$ fuse nominal current;

$I_{z}[\mathrm{~A}]$ - maximal permissible current of traction converter supply cable;

$I_{\text {cable }}=691[\mathrm{~A}]$ - nominal current of traction converter supply cable $150 \mathrm{~mm}^{2}$;

$K=0,776$ - reduction factor depend on: ambient temperature, installation type, cable conductor temperature, operation mode.

Proper cable protection against overload is verified is calculation below

$$
\begin{gathered}
1,6 \times I_{n} \leq 1,45 \times I_{Z} \\
1,6 \times 450 \leq 1,45 \times 536,21 \\
720[A] \leq 777,5[A]
\end{gathered}
$$

$I_{n}=350[\mathrm{~A}]-$ fuse nominal current;

$I_{z}=536,21[\mathrm{~A}]-$ maximal permissible current of traction converter supply cable.

\subsection{Scenario 4}

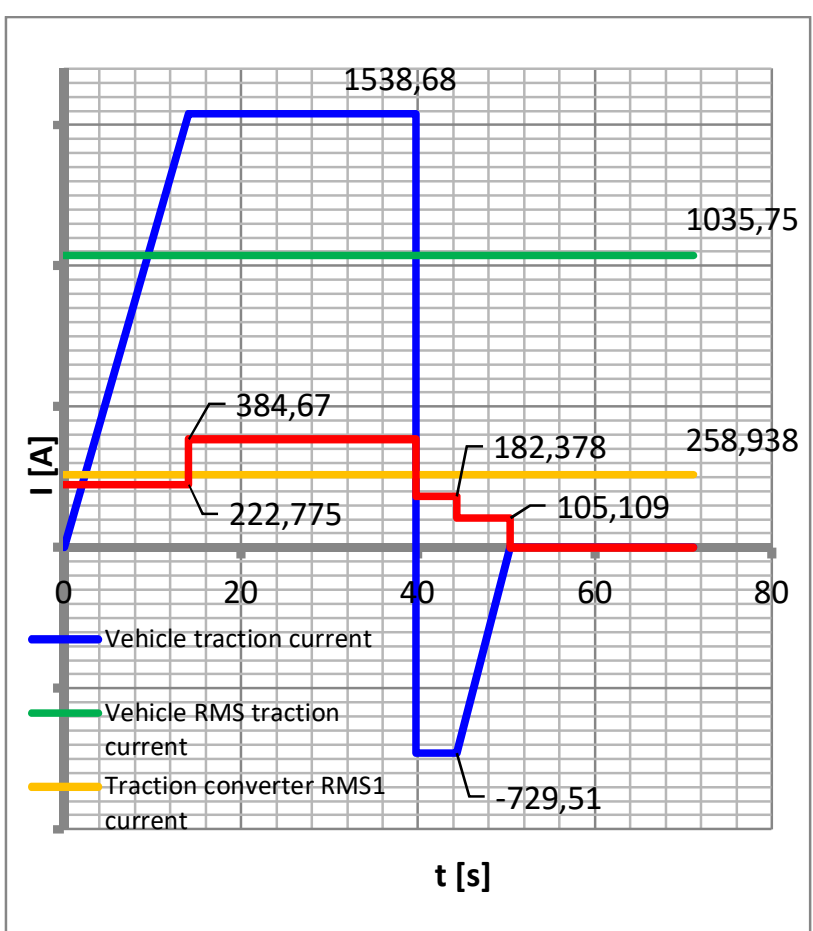

Fig. 5. Traction current and RMS current for vehicle and traction converter.

Fuse nominal current selection $\left(I_{n}\right)$.based on RMS1 current characteristic $\left(I_{B}\right)$

$$
I_{n} \geq I_{n \min }
$$




$$
\begin{gathered}
I_{\text {nmin }}=\frac{I_{B}}{A}=\frac{258,94}{0,462}=560,47[A] \\
I_{n}=630[A]
\end{gathered}
$$

$I_{B}=258,94[\mathrm{~A}]$ - traction converter input RMS current;

$I_{\text {rated }}[\mathrm{A}]$ - fuse minimal rated current;

$I_{n}[\mathrm{~A}]$ - fuse nominal current;

$A=0,462$ - reduction factor depend on: ambient temperature, ventilation air speed, operation mode.

For each driving phase RMS2 current should be compared with fuse let-through to eliminate fuse melting:

$$
\begin{gathered}
I_{T T C} \geq \frac{I_{B 1}}{B} \\
2800[A] \geq \frac{384,67[A]}{0,5} \\
2800[A] \geq 769,34[A]
\end{gathered}
$$

$I_{T T C}=2800[\mathrm{~A}]$ - fuse let-through current in $26[\mathrm{~s}]$ is defined according fuse time-current characteristic;

$I_{B I}=384,67[\mathrm{~A}]-$ traction converter input RMS current starting;

$B=0,5$ - fuse time-current characteristic reduction factor.

Cable selection is made in calculations below:

$$
\begin{gathered}
I_{n} \leq I_{z} \\
I_{z}=I_{\text {cable }} \times K \\
I_{z}=950 \times 0,776=737,2[A] \\
630[A] \leq 737,2[A]
\end{gathered}
$$

$I_{n}=630[\mathrm{~A}]-$ fuse nominal current;

$I_{z}[\mathrm{~A}]$ - maximal permissible current of traction converter supply cable;

$I_{\text {cable }}=950[\mathrm{~A}]-$ nominal current of traction converter supply cable $240 \mathrm{~mm}^{2}$;

$K=0,776$ - Reduction factor depend on: ambient temperature, installation type, cable conductor temperature, operation mode.

Proper cable protection against overload is verified is calculation below:

$$
\begin{gathered}
1,6 \times I_{n} \leq 1,45 \times I_{z} \\
1,6 \times 630 \leq 1,45 \times 737,2 \\
1008[A] \leq 1069,94[A]
\end{gathered}
$$

$I_{n}=630[\mathrm{~A}]-$ fuse nominal current;

$I_{z}=737,2[\mathrm{~A}]$ - maximal permissible current of traction converter supply cable.

\section{Conclusions}

Table 2 presents summary of scenario simulations and differences in selected components provided by differ approaches in simulations of effective current values.

Table 2. Summary of simulations.

\begin{tabular}{|c|c|c|c|c|}
\hline $\begin{array}{c}\text { Component } \\
\text { parameter }\end{array}$ & $\begin{array}{c}\text { Scenario } \\
1\end{array}$ & $\begin{array}{c}\text { Scenario } \\
2\end{array}$ & Scenario 3 & $\begin{array}{c}\text { Scenario } \\
4\end{array}$ \\
\hline $\begin{array}{c}\text { Nominal } \\
\text { current [A] }\end{array}$ & 315 & 400 & 450 & 630 \\
\hline $\begin{array}{c}\text { Fuse size } \\
W x L x H[\mathrm{~mm}]\end{array}$ & $\begin{array}{c}60 \times 206 \times \\
60\end{array}$ & $\begin{array}{c}60 \times 206 \times 6 \\
0\end{array}$ & $\begin{array}{c}73 \times 206 \times 7 \\
3\end{array}$ & $\begin{array}{c}73 \times 206 \times 7 \\
3\end{array}$ \\
\hline $\begin{array}{c}\text { Fuse weight } \\
(1 \mathrm{szt})[\mathrm{kg}]\end{array}$ & 1,34 & 1,34 & 1,98 & 1,98 \\
\hline $\begin{array}{c}\text { Cable CSA } \\
{\left[\mathrm{mm}^{2}\right]}\end{array}$ & 95 & 120 & 150 & 240 \\
\hline $\begin{array}{c}\text { Cable diameter } \\
{[\mathrm{mm}]}\end{array}$ & 17,3 & 19,6 & 21,9 & 29,9 \\
\hline $\begin{array}{c}\text { Cable weight } \\
(250 \mathrm{~m})[\mathrm{kg}]\end{array}$ & 242,5 & 312,5 & 387,5 & 612,5 \\
\hline $\begin{array}{c}\text { Notes: } 250 \mathrm{~m} \text { is assumed length value of main circuit cable } \\
\text { (power supply circuit and return circuit) for simulated tram } \\
\text { vehicle. }\end{array}$ \\
\hline
\end{tabular}

Scenario which could be used for further design is scenario 2 which should be the most realistic in terms of real tram operation estimation.

The conclusion is that it is very important at the beginning of project to agree necessary information with tram operator to be sure that simulation parametrization correctly estimate further tram operations. Such deep optimization has also negative effects design is assign to infrastructure of one operator, in future if tram operator would like to sold it to other city it need to be check if some adjustment has to be performed to fit with new scenarios. To omit such situation it would be good to develop common methodology to model effective currents in trams that's all tram vehicles will have common performance and be easy to redistribute after certain ears of operation.

\section{References}

1. EN 50343:2014 Railway applications - Rolling stock Rules for installation of cabling

2. EN 50355:2013 Railway applications - Railway rolling stock cables having special fire performance - Guide to use

3. EN 60077-1:2003 Railway applications - Electric equipment for rolling stock - Part 1: General service conditions and general rules

4. EN 60077-2:2003 Railway applications - Electric equipment for rolling stock - Part 2: Electrotechnical components - General rules

5. EN 60077-5:2004 Railway applications - Electrotechnical equipment for rolling stock - Part 5: Electrotechnical components - Rules for HV fuses

6. HD 60364-4-43:2010 Low-voltage electrical installations Part 4-43: Protection for safety - Protection against overcurrent

7. Team of Authors, 2007 The Fuse Manual-Ultra-rapid Fuses SIBA-, edited by Siba, Lünen 